\title{
An elevated large-scale dust veil from the Taklimakan Desert: Intercontinental transport and three-dimensional structure as captured by CALIPSO and regional and global models
}

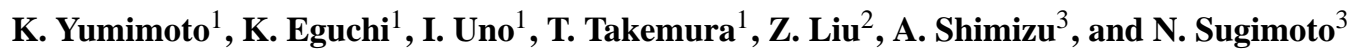 \\ ${ }^{1}$ Research Institute for Applied Mechanics, Kyushu University, Fukuoka, Japan \\ ${ }^{2}$ National Institute of Aerospace, Hampton, Virginia, USA \\ ${ }^{3}$ National Institute for Environmental Studies, Tsukuba, Japan
}

Received: 22 April 2009 - Published in Atmos. Chem. Phys. Discuss.: 3 July 2009

Revised: 28 October 2009 - Accepted: 2 November 2009 - Published: 11 November 2009

\begin{abstract}
An intense dust storm occurred during 1920 May 2007 over the Taklimakan Desert in northwestern China. Over the following days, the space-borne lidar CALIOP tracked an optically thin, highly elevated, horizontally extensive dust veil that was transported intercontinentally over eastern Asia, the Pacific Ocean, North America, and the Atlantic Ocean. A global aerosol transport model (SPRINTARS) simulated the dust veil quite well and provided a three-dimensional view of the intercontinental dust transport. The SPRINTARS simulation revealed that the dust veil traveled at $4-10 \mathrm{~km}$ altitudes with a thickness of $1-4 \mathrm{~km}$ along the isentropic surface between 310 and $340 \mathrm{~K}$. The transport speed was about $1500 \mathrm{~km} /$ day. The estimated dust amount exported to the Pacific was $30.8 \mathrm{Gg}$, of which $65 \%$ was deposited in the Pacific and $18 \%$ was transported to the North Atlantic. These results imply that dust veils can fertilize open oceans, add to background dust, and affect the radiative budget at high altitudes through scattering and absorption.

The injection mechanism that lifts dust particles into the free atmosphere is important for understanding the formation of the dust veil and subsequent long-range transport. We used a regional dust transport model (RC4) to analyze the dust emission and injection over the source region. The RC4 analysis revealed that strong northeasterly surface winds associated with low pressures invaded the Taklimakan Desert through the eastern corridor. These winds then formed strong
\end{abstract}

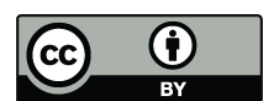

Correspondence to: K. Yumimoto (yumimoto@riam.kyushu-u.ac.jp) upslope wind along the high, steep mountainsides of the Tibetan Plateau and blew large amounts of dust into the air. The updraft lifted the dust particles farther into the upper troposphere (about $9 \mathrm{~km}$ above mean sea level, MSL), where westerlies are generally present. The unusual terrain surrounding the Taklimakan Desert played a key role in the injection of dust to the upper troposphere to form the dust veil.

\section{Introduction}

It is well known that Asian dust impacts regional and remote air quality and climate over eastern Asia, the Pacific Ocean, and beyond (Husar et al., 2001; McKendry et al., 2001; Yu et al., 2003). The Taklimakan Desert, which is located in the Tarim Basin and bounded on three sides by high mountains, is one of the largest deserts in the world, covering $\sim 320000 \mathrm{~km}^{2}$. It is considered to be a major source of the dust transported into the North Pacific. Sun et al. (2001) suggested that dust materials from the Taklimakan Desert can be lifted over $5 \mathrm{~km}$ and transported over long distances by westerlies. Bory et al. (2003) compared the mineralogical and isotopic characteristics of mineral dust deposits in northern Greenland and in China and Mongolia, and suggested that the Taklimakan Desert is a primary dust source during spring. By analyzing three independent datasets $(\mathrm{Nd}$ isotopic composition measurement, back-trajectory, and numerical model simulations), Grousset et al. (2003) suggested that the dust event observed on 6 March 1990 in the Alps was very likely to have originated in the Taklimakan Desert. Matsuki et al. (2003) analyzed aircraft and lidar measurements

Published by Copernicus Publications on behalf of the European Geosciences Union. 
over central Japan and found that the Taklimakan Desert was also an important source of atmospheric background dust. However, direct observational evidence of intercontinental transport of Asian dust to Europe is lacking, so there is little support for these findings. In addition, the uplifting mechanism of dust particles into the high troposphere over the Taklimakan Desert, which leads to the subsequent long-range transport, requires more detailed exploration.

Long-range transport of dust particles affects Earth's radiative budget both directly through scattering and absorbing solar radiation (Bohren and Huffman, 1983; Sokolic and Toon, 1996) and indirectly through changes in cloud physical and radiative properties as cloud condensation nuclei (Twomey, 1977; Sassen, 2002). Through deposition, transported dust also acts as a source of nutrients for marine plankton in upper ocean waters (Martin et al., 1994; Duce et al., 1991). To estimate these effects accurately, extensive measurements of dust transport altitudes, patterns, and lifetimes are required. Passive satellite observations (e.g. the Total Ozone Mapping Spectrometer, TOMS, Aerosol Index and Moderate Resolution Imaging Spectroradiometer, MODIS, aerosol optical thickness data) have provided useful information on dust horizontal transport. However, observation of the three-dimensional (3-D) distribution (particularly the vertical structure) of dust transport using these passive measurements is difficult.

The space-based Cloud-Aerosol Lidar with Orthogonal Polarization (CALIOP) aboard the Cloud-Aerosol Lidar and Infrared Pathfinder Satellite Observation (CALIPSO) launched on 28 April 2006 provides new information on the global vertical distributions of aerosols and clouds (Winker et al., 2007). CALIOP offers a unique opportunity to measure dust vertical distributions globally through depolarization ratio measurements. Using CALIOP observations, Liu et al. (2008a) presented a study of a large-scale dust plume that originated in the Saharan Desert and was transported across the North Atlantic into the Gulf of Mexico in the lower troposphere $(<7 \mathrm{~km})$ in 10 days. Seasonal 3-D distributions of airborne dust over East Asia have been derived from the first year of CALIOP measurements (Liu et al., 2008b). Dust distributions and seasonality are influenced significantly by the unique orography of the Tibetan Plateau. Huang et al. (2008) investigated the vertical structures of Asian dust based on CALIOP observations during the Pacific Dust Experiment (PACDEX). However, it is difficult to capture detailed 3-D structures and daily variations using CALIOP measurements alone because of the large longitudinal interval between two consecutive CALIPSO orbits $(\sim 1000 \mathrm{~km}$ at mid-latitudes). Comprehensive studies are required of each dust source to understand its role in Asian dust generation and transport. Recently, Uno et al. (2008, 2009), Generoso et al. (2008), and Eguchi et al. (2009) performed integrated analyses using CALIOP measurements and numerical model simulations, providing more detailed observations of the 3-D structures of Asian and Saharan dust transport.
An intensive dust storm occurred on 19-20 May 2007 in the Taklimakan Desert. Over the following days, CALIOP detected an optically thin, highly lofted, extensive dust layer, which was transported over eastern Asia, the Pacific Ocean, North America, and the Atlantic Ocean. We call this type of dust layer a "dust veil" to emphasize its vertically thin and horizontally extensive structure. In this study, we comprehensively investigated the emission and injection processes over the source region, the subsequent intercontinental transport, and the 3-D structure of the dust veil. We combined regional and global aerosol transport models, in situ measurements, and passive and active satellite observations.

The models and observation data used in this study are described in Sect. 2. A detailed analysis of the emission and injection processes over the Taklimakan Desert using a regional dust model is presented in Sect. 3, along with analysis of the global transport and 3-D structure of the dust veil. We present our conclusions in Sect. 4.

\section{Numerical models and observation datasets}

\subsection{Numerical models}

We used global and regional numerical models in our analyses. The regional model (with finer horizontal and vertical resolutions) was used for a detailed analysis of the emission and injection of the dust veil from the Taklimakan Desert. The subsequent intercontinental transport of the dust veil was analyzed using the global aerosol transport-radiation model.

The Regional Atmospheric Modeling System/Chemical Weather Forecast System with four-dimensional variational data assimilation system (RAMS/CFORS-4DVAR) regional dust transport model (RC4; Yumimoto et al., 2007, 2008) was used to analyze dust veil generation over the source region. RC4 is based on the successful RAMS/CFORS dust model (Uno et al., 2004). The RC4 domain was located over eastern Asia (Fig. 1), with a horizontal resolution of $40 \mathrm{~km}$ and 55 vertical stretching layers from the surface to $20 \mathrm{~km}$ (a vertical resolution of $140 \mathrm{~m}$ at the surface and $400 \mathrm{~m}$ at the top). To investigate the dust veil origin, dust emissions were limited to those over the Taklimakan Desert. In addition, to understand visually how dust particles were injected into high altitudes over the Tarim Basin, we also performed a simplified wind-driven tracer simulation with wind fields obtained from the RAMS/CFORS simulation. In the tracer simulation, dust tracers were emitted from the surface when the surface wind speed became greater than $6.5 \mathrm{~m} / \mathrm{s}$ and were then transported by the modeled wind fields. The number of emitted tracers was proportional to the cube of the surface wind speed. The threshold wind speed and third power-law relation were based on the results of both surface observations (e.g. Kurosaki and Mikami, 2003) and numerical models (e.g. Tegen and Fung, 1994; Takemura et al., 2005). 


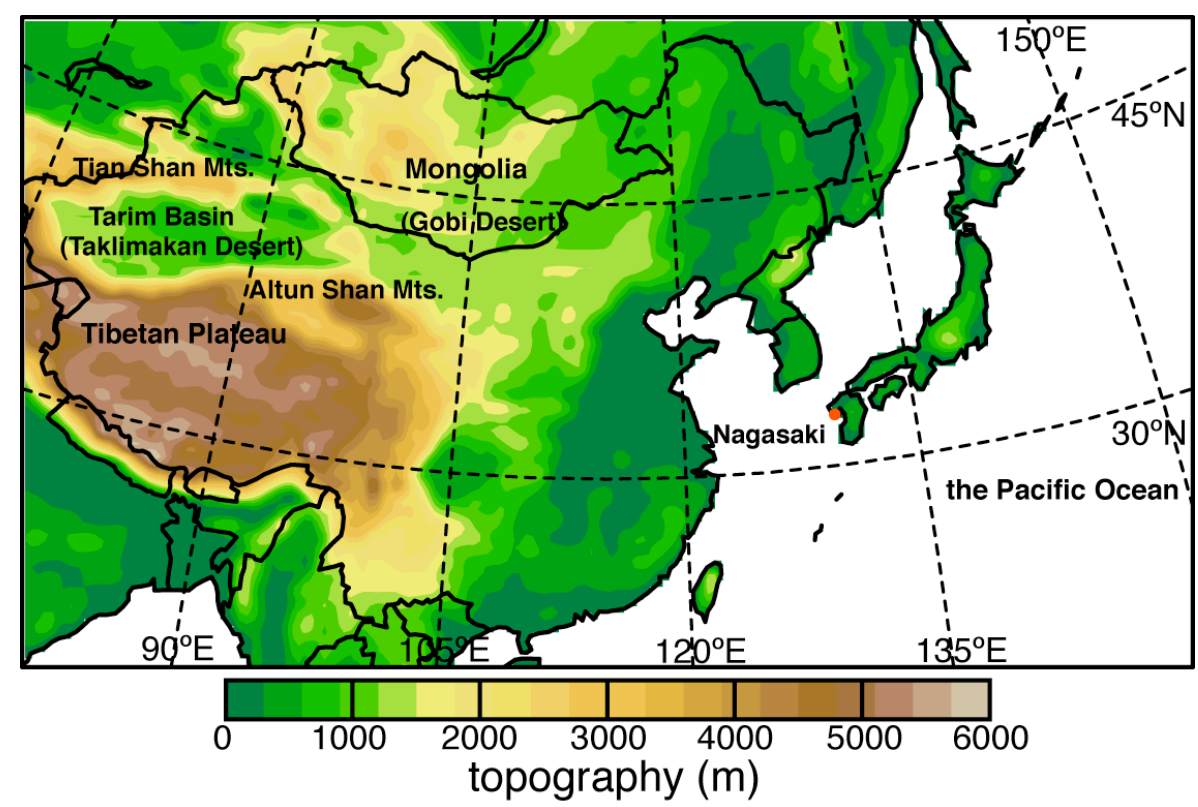

Fig. 1. The RC4 modeling domain and topography of the Taklimakan Desert.

The global Spectral Radiation-Transport Model for Aerosol Species (SPRINTARS; Takemura et al., 2005) was used in this study. SPRINTARS includes explicit estimates of the direct, first indirect, and second indirect effects of aerosols. The horizontal resolution was T106, with 56 layers in a sigma coordinate. To focus on the transport of the dust veil from the Taklimakan Desert, emissions from all other regions (e.g. the Gobi Desert, Mongolia, or Inner Mongolia) were neglected.

Both the regional and global model simulations were nudged by $2.5^{\circ} \times 2.5^{\circ}$ National Centers for Environmental Prediction/National Center for Atmospheric Research (NCEP/NCAR) reanalysis data, with a time interval of $6 \mathrm{~h}$. The reanalysis data were also used for the meteorological boundary conditions of RAMS.

\subsection{Observational data}

\subsubsection{CALIOP}

The space-based lidar CALIOP, which was launched on 28 April 2006 aboard CALIPSO, provides vertical distributions of aerosol and clouds on a global scale (Winker et al., 2007). For comparison with the model simulations, we retrieved vertical profiles of the dust extinction coefficient from the total attenuated backscatter contained in the Level 1B CALIOP data (ver. 2.01), using Fernald's inversion (Fernald, 1984) by setting the lidar ratio $\mathrm{S} 1=50 \mathrm{sr}$ (Shimizu et al., 2004). Then, the retrieved vertical profiles were averaged to the resolution of the CALIOP Level 2 data $(5 \mathrm{~km})$. The cloud-aerosol discrimination (CAD) index in the Level 2
CALIOP data was used for cloud layer detections. Our method of CALIOP data processing was identical to those of Uno et al. (2008, 2009), Hara et al. (2009), and Eguchi et al. (2009).

\subsubsection{NIES lidar network}

The National Institute for Environmental Studies (NIES) lidar network (Shimizu et al., 2008) consists of 21 standard lidar observation sites distributed over Japan, Korea, China, Mongolia, and Thailand. It provides vertical profiles of aerosols and clouds with a high temporal resolution (15 min). Observation results are displayed in real time at http://soramame.taiki.go.jp/dss/kosa/ and have been used for inverse modeling of Asian dust in combination with a numerical model (Yumimoto et al., 2007, 2008). Shimizu et al. (2004) have provided a detailed description of the NIES lidar data processing.

\subsubsection{Other observations}

We also used Aerosol Index (AI) measurements from the Ozone Monitoring Instrument (OMI) to examine the horizontal distributions of dust loading over the source region. The OMI AI provides a semi-quantitative estimate of columnar aerosol loading in a given pixel. A positive AI value indicates the presence of UV-absorbing aerosols (Prospero et al., 2002). The World Meteorological Organization (WMO) SYNOP data (wind speed, wind direction, visibility, and weather) were also used to investigate the emission of dust from the Taklimakan Desert. Shao et al. (2003) found the 


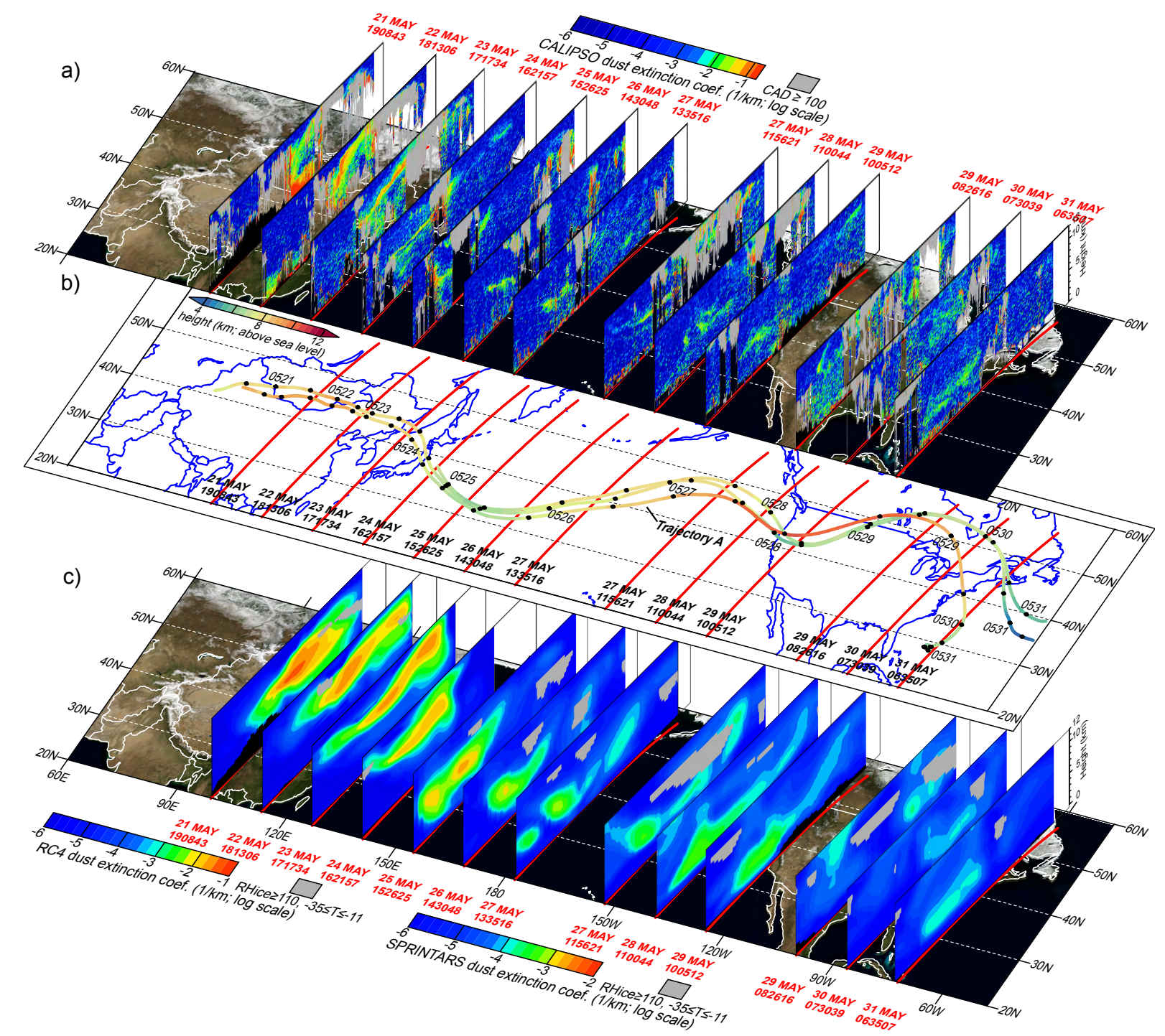

Fig. 2. Three-dimensional analysis of intercontinental transport of the dust veil. (a) Cross-sections of the CALIOP dust extinction coefficient with the cloudy regions shaded in gray (CAD>100). (b) HYSPLIT forward and backward trajectories started at 17:00 UTC on 24 May at $36-38^{\circ} \mathrm{N}$ and $145-146^{\circ} \mathrm{E} 7000 \mathrm{~m}$ above sea level on the 24 May-162157 CALIPSO orbit. The colors represent trajectory heights. (c) Cross-sections of the model-simulated dust extinction coefficient. The first four cross-sections over eastern Asia during 21-24 May were simulated the RC4 model, while the rest were derived from the SPRINTARS model. Gray shaded areas represent regions that satisfy the condition of heterogeneous ice formation for mineral dust particles: relative humidity with respect to ice $\left(\mathrm{RH}_{\mathrm{ice}}\right)>110 \%$, and $-35^{\circ} \mathrm{C}<$ temperature $(T)<-11^{\circ} \mathrm{C}$. The color scale ranges for CALIOP, RC4, and SPRINTARS are not consistent.

following empirical relationships between visibility and dust concentrations by fitting near-surface total suspended particle (TSP) measurements to visibilities:

$C_{\mathrm{SYNOP}}=3802.29 V_{\mathrm{SYNOP}}^{-0.85}$ for $V_{\mathrm{SYNOP}}<3.5$

$C_{\mathrm{SYNOP}}=\exp \left(-0.11 V_{\mathrm{SYNOP}}+7.62\right)$ for $V_{\mathrm{SYNOP}}>3.5$

where $C_{\text {SYNOP }}$ is the dust concentration $\left(\mu \mathrm{g} / \mathrm{m}^{3}\right)$, and $V_{\text {SYNOP }}$ is the SYNOP visibility $(\mathrm{km})$. Because $C_{\mathrm{SYNOP}}$ is based on an empirical equation, it is sometimes difficult to estimate the absolute concentration level.

\section{Results and discussion}

Figure 2a shows transects of the CALIOP dust extinction coefficient during 21-30 May 2007. The CALIOP tracked a very thin, highly elevated, large-scale dust veil from the Taklimakan Desert to the North Atlantic Ocean (yellowishgreen features at high altitudes in the vertical transects of the CALIOP extinction coefficients). In the following subsections, we discuss emission and injection processes over the Tarim Basin from 17 to 22 May when the dust veil formed. 

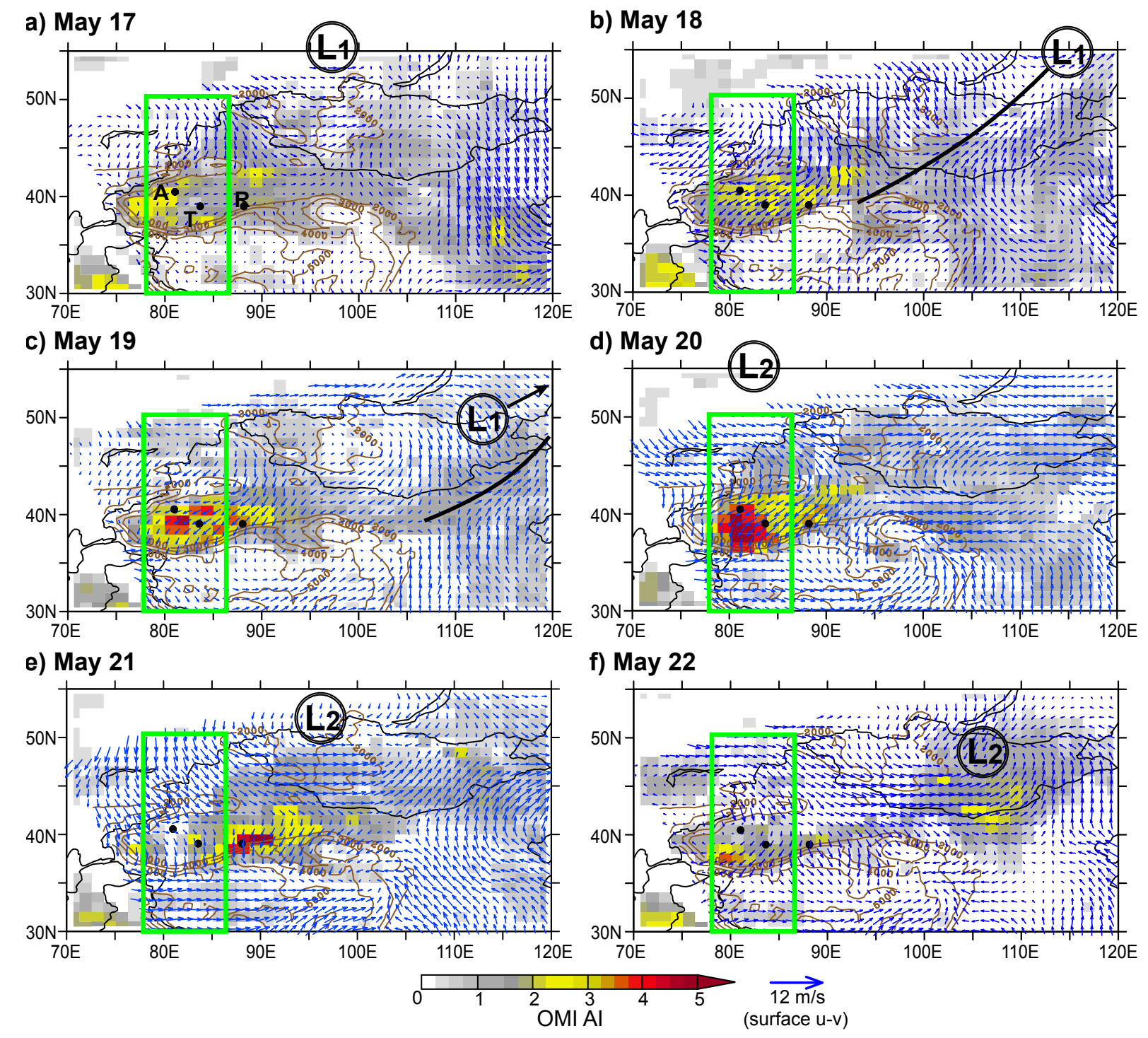

f) May 22

Fig. 3. OMI AI (color), the RC4 simulated daily averaged surface wind (blue vectors), and the topography (brown contours). The locations of low pressure regions (circled character L) and associated cold fronts (solid black lines), which were estimated from the pressure at mean sea level in the $2.5^{\circ} \times 2.5^{\circ} \mathrm{NCEP} / \mathrm{NCAR}$ reanalysis product, the MODIS true color image (also see Fig. 6), and the RC4 results are also shown. The SYNOP observation stations are also shown in (a) as black solid circles: Alar (A: $\left.81.1^{\circ} \mathrm{E}, 40.5^{\circ} \mathrm{N}\right)$, Tazhong $\left(\mathrm{T}: 83.7^{\circ} \mathrm{E}, 39.0^{\circ} \mathrm{N}\right)$, and Ruoqiang (R: $\left.88.2^{\circ} \mathrm{E}, 39.0^{\circ} \mathrm{N}\right)$.

We then present results on the 3-D structure of the intercontinental dust veil transport.

\subsection{Emission and injection of the dust veil}

The emission and injection of dust into the air over the source region were very important for the formation of the dust veil and its subsequent long-range transport. We performed a comprehensive analysis to investigate these processes using multiple measurement datasets and analysis tools. Figure 3 shows the meteorological conditions over the Tarim Basin from the RC4 regional model simulation with distributions of OMI AI during 17-22 May. Figure 4 presents dailyaveraged cross-sections of wind fields for the regions indicated by the green rectangles in Fig. 3. For visualization of the injection process, results from the simplified wind-driven tracer simulations are also shown. The tracer distributions agree quite closely with those of the modeled dust extinction coefficients. Figure 5 shows the simulated RC4 and reported SYNOP surface wind speeds and directions at the three SYNOP stations Alar, Tazhong, and Ruoqiang, which were located respectively in the northern, middle, and eastern 
regions of the Taklimakan Desert (marked by letters A, T, and $\mathrm{R}$ in Fig. 3). Dust concentrations derived from SYNOP visibilities and RC4 surface dust concentrations are also shown.

On 17 May, a low pressure region $\left(\mathrm{L}_{1}\right)$ was in northern Mongolia, as shown in Fig. 3a. At this time, strong northern winds were produced over the northern side of the Tarim Basin, but the air inside the basin was still calm. The tracer simulation showed that only a small amount of dust tracers were emitted from the surface to the basin (Fig. 4a). The three SYNOP stations reported weak surface winds $(\leq 3 \mathrm{~m} / \mathrm{s}$; not shown).

On 18 May (Figs. 3b and 4b), cold northerly surface winds associated with the low pressure $\mathrm{L}_{1}$ became stronger over northwestern China. Forced by the Tibetan Plateau, these winds changed direction and blew into the basin along the corridor on the eastern side. Meanwhile, a cold front formed over Mongolia, as indicated by the black line in Fig. $3 \mathrm{~b}$. OMI AI levels were still low over the desert. In the tracer simulation (Fig. 4b), strong surface winds began to sweep a significant amount of dust into the air, and the top of the dust plume reached the height of the Tibetan Plateau. At SYNOP stations, both the wind speed and direction changed suddenly, and a strong northeasterly wind formed in the basin, consistent with the RC4 simulated wind fields (Fig. 5).

On 19 May (Figs. 3c and 4c), strong wind blasted toward the southern side of the basin and produced upslope winds (about $0.2 \mathrm{~m} / \mathrm{s}$ in the vertical direction). The windblown dust tracers were then carried up to free atmosphere by the upward wind along the northern slope of the Tibetan Plateau. At this point, the OMI AI became larger over the basin. SYNOP stations, except the northern station at Alar, reported strong surface winds $(>5 \mathrm{~m} / \mathrm{s})$ and low visibilities $(<3 \mathrm{~km})$. Particularly at Ruoqiang, considerably low visibility $(<1 \mathrm{~km})$ persisted for $15 \mathrm{~h}$.

On 20 May (Figs. 3d and 4d), the strong surface wind continued to inject dust tracers into the atmosphere. The OMI AI indicated that dense dust spread over the entire basin. The uplifted particles reached an altitude of $\sim 9 \mathrm{~km}$ and were captured within the $320-340 \mathrm{~K}$ potential temperature zone. They were subsequently transported eastward by the strong westerly wind $(>20 \mathrm{~m} / \mathrm{s})$ and started their intercontinental travel. SYNOP stations reported that strong surface winds $(>5 \mathrm{~m} / \mathrm{s})$ persisted over the basin on this day. Following the low pressure $\mathrm{L}_{1}$, another low pressure region $\left(\mathrm{L}_{2}\right)$ appeared north of the basin.

On 21 May (Figs. 3e and 4e), the OMI AI showed that most of the dust loading had been transported eastward out of the basin. At Tazhong (center) and Ruoqiang (east), the wind direction changed quickly from easterly to westerly. SYNOP reported rain at all three stations, indicating a widespread rain event within the basin.

On 22 May (Figs. 3f and 4f), OMI AI indicated that the dust has been transported to Mongolia and had become weaker. Meanwhile, another dust storm occurred in the basin, associated with the second low pressure region $\left(\mathrm{L}_{2}\right)$.
This dust storm appeared to be weaker than the first one. SYNOP stations observed higher visibilities over the basin $(\geq 6 \mathrm{~km})$.

Aoki et al. (2005) classified the mesoscale cold wind that produces dust storms in the Tarim Basin into three patterns. The wind that produced the dust veil studied here may be identified as Pattern 1. This pattern is characterized by an easterly mesoscale surface wind, which is separated from the synoptic-scale cold westerly. The surface cold wind changes its direction to westward after going around the eastern side of the Tian Shan range (compare Figs. 5 and 3 of Aoki et al., 2005). Eguchi et al. (2009) reported another case of long-range transport of Taklimakan dust occurring during 810 May 2007 that fit Pattern 1. The high and steep mountainside terrain of the Tibetan Plateau on the southern side of the basin plays a key role in forming the strong updraft that carries dust particles into the upper troposphere for long-range transport by westerlies.

To investigate the evolution of dust veil transport in the upper troposphere (9-12 km) during the first few days, Fig. 6 shows a day-by-day overview of the RC4 simulated dust aerosol optical depth (AOD), wind field at $\sim 8 \mathrm{~km}$ above mean sea level (MSL), center locations of the low pressures, and cloud distribution observed by MODIS/AQUA over eastern Asia. Longitudinal vertical transects of the RC4 dust extinction coefficients and potential temperature are also shown. Note that the RC4 simulation shown in Fig. 6 allowed only dust emission from the Taklimakan Desert.

On 21 May (Fig. 6a), dust was injected into the upper troposphere, reaching an altitude of $9 \mathrm{kmm}$.s.l. at 04:00 UTC (also see Fig. 4e). At 19:00 UTC, CALIOP passed over the Gobi Desert and detected two dense dust layers (Figs. 7a and 2a: 21 May-190843 path). One dust layer was near the surface, while the other was at an altitude of $6-10 \mathrm{~km}$. The RC4 simulation (Figs. 7b and 2c: 21 May-190843 path), which only considered dust emissions from the Taklimakan Desert, reproduced only one dust layer at higher altitudes, indicating that the upper dust layer observed by CALIOP originated in the Taklimakan Desert. The lower layer should have been generated by other sources (very likely the Gobi Desert).

On 22 May, the eastward transport of the dust increased in speed within the westerly (upper panel of Fig. 6b; also see the OMI AI distribution in Fig. 3f). The vertical crosssection (lower panel in Fig. 6b) shows that the dust loading was transported across the Altun Shan range in the northeastern Tibetan Plateau (Fig. 1) with a thin structure within a potential temperature zone of 320-340 K. CALIOP (Fig. 2a: 22 May-181306 path) also detected a thin dust layer at 6$12 \mathrm{~km}$ on this day.

On 23 May (Fig. 6c), the low pressure region $\mathrm{L}_{2}$ was deepening and forming a cold front over the Gobi Desert. The modeled AOT horizontal distribution (upper panels in Fig. 6c) shows that the dust veil was transported in front of the $\mathrm{L}_{2}$ cold front extending in the north-south direction through the meandering westerly. The vertical cross-section 
a) May 17

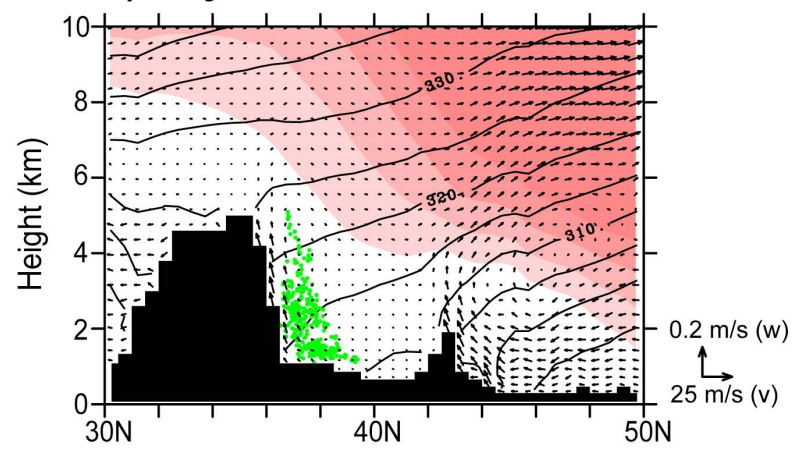

c) May 19

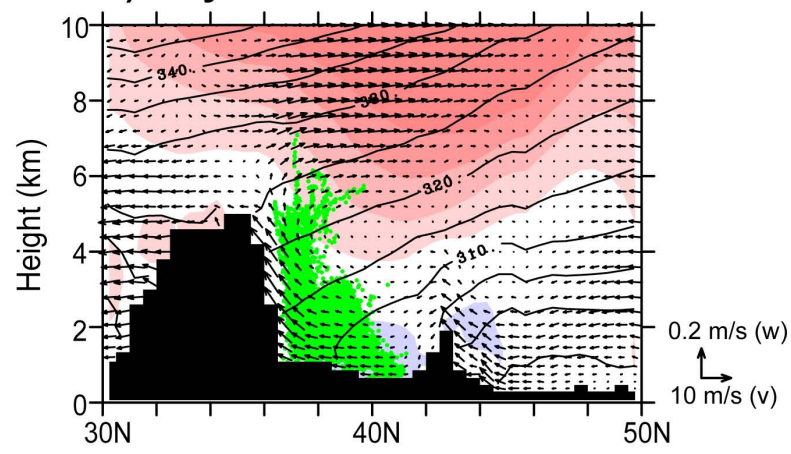

e) May 21

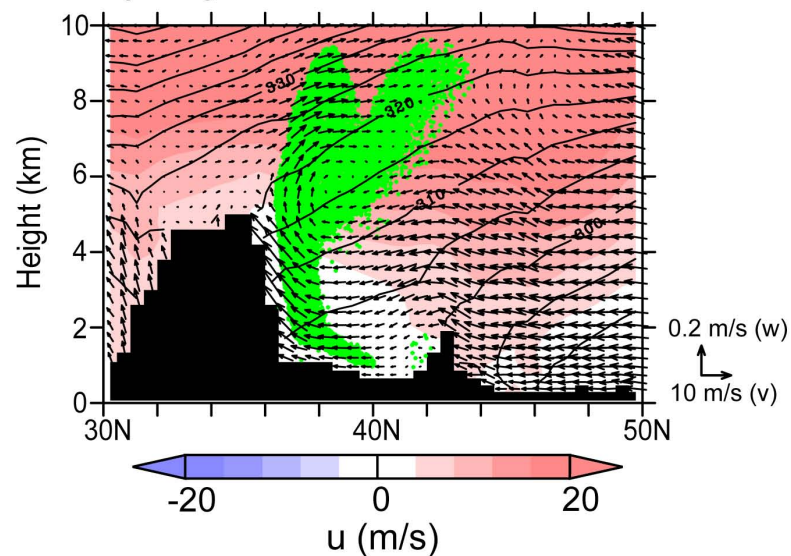

b) May 18

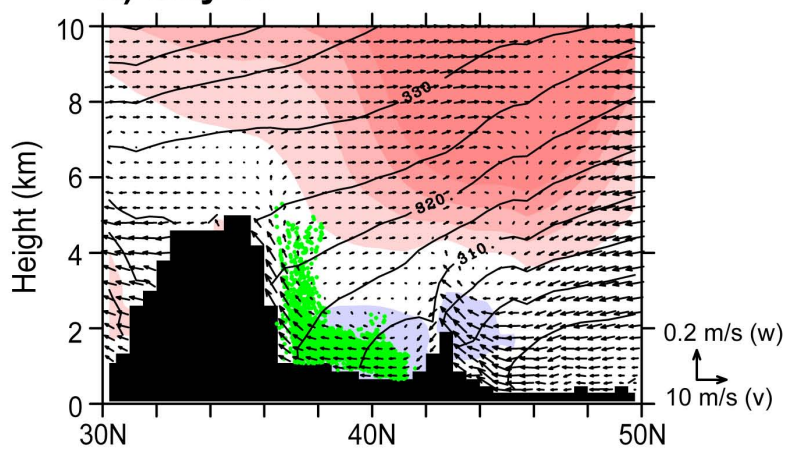

d) May 20

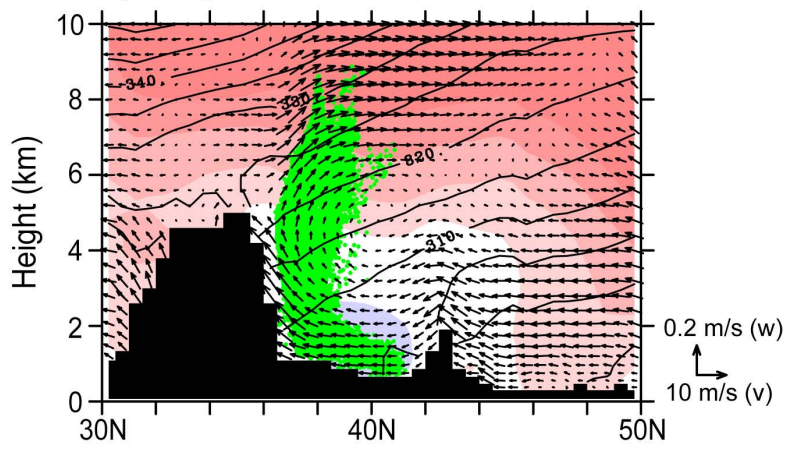

f) May 22

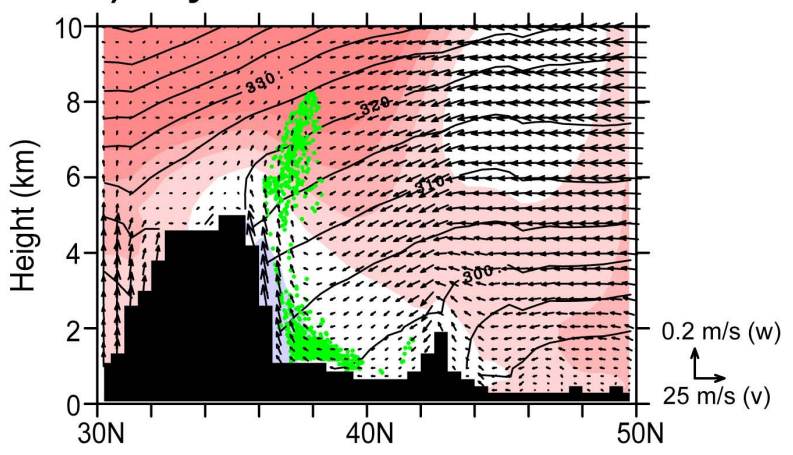

- : tracers emitted from the surface when wind speed exceeds $6.5 \mathrm{~m} / \mathrm{s}$

Fig. 4. Averaged cross-sections of wind fields for the regions indicated by green rectangles in Fig. 3. Green dots represent distributions of dust tracers from the simple wind-driven tracer simulation. Colored contours depict the daily-averaged wind speed in the east-west direction. Black contours represent the daily-averaged potential temperatures.

(lower panel in Fig. 6c) shows that the lower part of the dust remained behind the $\mathrm{L}_{2}$ cold front near $115^{\circ} \mathrm{E}$, whereas the upper part (i.e. the dust veil) was transported beyond the cold front. This indicates that the dust veil in the upper troposphere could travel faster than lower dust clouds (e.g. the Gobi dust, which was transported typically at altitudes $<5 \mathrm{~km}$ ). Eguchi et al. (2009) reported a Taklimakan dust layer that was transported at $\sim 10 \mathrm{~km}$ and caught up with a Gobi dust layer generated 5 days earlier, forming a twolayered dust distribution over the eastern North Pacific.
On 24 May (Fig. 6d), the dust veil was transported farther between $L_{2}$ and $L_{1}$ along the westerly, with its front part reaching Japan. The cross-section showed that the dust veil traveled at $6-11 \mathrm{~km}$ altitude within the isentropic surface of potential temperature $320-340 \mathrm{~K}$. In the following days, the dust veil continued its long journey to North America and the North Atlantic, as discussed in the following subsection. 


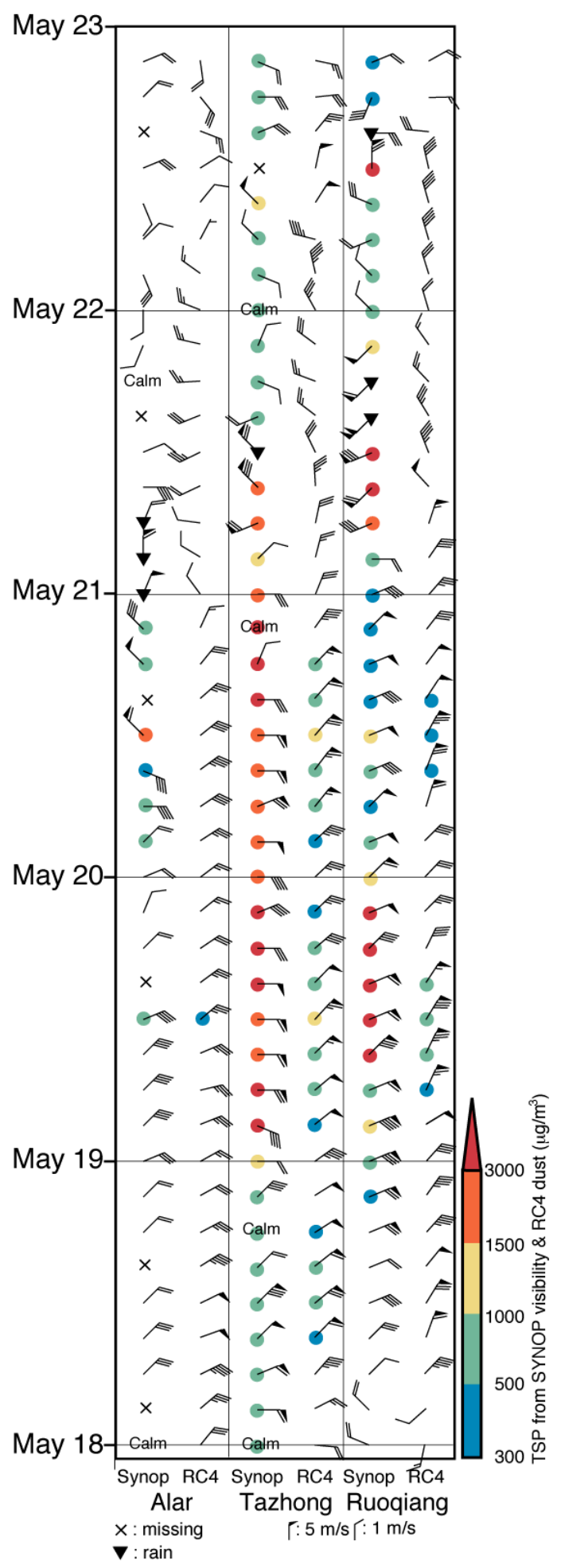

Fig. 5. Time series of the SYNOP-observed and RC4-simulated surface wind speed and direction during 18-21 May at Alar, Tazhong, and Ruoqiang (see Fig. 3). Dust concentrations derived from visibilities and rain events are shown as symbols. The RC4 simulated surface dust concentrations are also shown.

\subsection{Intercontinental transport}

As shown in Fig. 2a, CALIOP captured the intercontinental transport of the dust veil from the Taklimakan Desert to the North Atlantic Ocean during 20-31 May 2007. Corresponding vertical transects of the model-simulated dust extinction coefficients are presented in Fig. 2c. In that figure, four transects over eastern Asia during 21-24 May were derived from RC4, while the rest were from SPRINTARS. Together, the two models tracked the dust veil transcontinental transport quite well. In addition, we performed a preliminary SPRINTARS simulation in which the dust emission of the Taklimakan Desert was eliminated and other aerosol sources (sulfate, sea salt, carbonaceous particles, and dust from non-Taklimakan Desert sources) were included. The non-Taklimakan dust simulation could not capture the dust veil measured by CALIOP (not shown). This indicates that dust from other sources (i.e. the Gobi Desert) and non-dust aerosols could not be carried to such a high altitude, and hence did not contribute to the dust veil formation. Figure $2 \mathrm{~b}$ shows forward and backward trajectories by the $\mathrm{Hy}$ brid Single Particle Lagrangian Integrated Trajectory (HYSPLIT) Model (Draxler and Hess, 1998). The trajectories show the long journey of the dust veil from the Taklimakan Desert, over the North Pacific and North America, and into the North Atlantic Ocean.

The two panels in Fig. 8b present vertical cross-sections of the dust extinction coefficients measured by CALIOP and simulated by the RC4 model along the CALIPSO track on 23 May in Fig. 8a. The NIES lidar at Nagasaki $\left(129.98^{\circ} \mathrm{E}\right.$, $32.94^{\circ} \mathrm{N}$ ) also detected a 1-km-thick dust veil passing overhead at 6-7 km altitude during the night of 23-24 May (left panel in Fig. 8c). For comparison, the RC4 simulated dust extinction coefficient at Nagasaki is also presented in the right panel of Fig. 8c. The height, thickness, and passage time of the dust measured by the NIES lidar were consistent with those measured by CALIOP. The RC4 model captured similar, but considerably underestimated, dust veil characteristics.

Figure 9a shows a longitudinal cross-section of the SPRINTARS dust extinction coefficient and potential temperature along the HYSPLIT trajectory from the Taklimakan Desert to the North Atlantic Ocean. Figure 9b (lower panels) compares averaged vertical profiles of dust extinction coefficients along the CALIOP orbit paths at $\sim 145^{\circ} \mathrm{E}$ (eastern Asia), $5^{\circ} \mathrm{W}$ (the date line), and $70^{\circ} \mathrm{W}$ (Atlantic Ocean). The vertical profiles are normalized by the maximum values.

The SPRINTARS dust extinction coefficient (Fig. 9a) shows that the dust veil formed over the Taklimakan Desert was transported eastward at $5-10 \mathrm{~km}$ along the isentropic surface of 310-340 K over eastern Asia. CALIOP observed a thin dust layer of $<1 \mathrm{~km}$ on 24 May (the left panel of Fig. 9b; see also Fig. 2). However, the models were unable to capture the fine structure of the dust layer due to their low vertical resolution. Compared to the CALIOP and $\mathrm{RC} 4$ profiles, the 
a) 21 May 2007, 04UTC

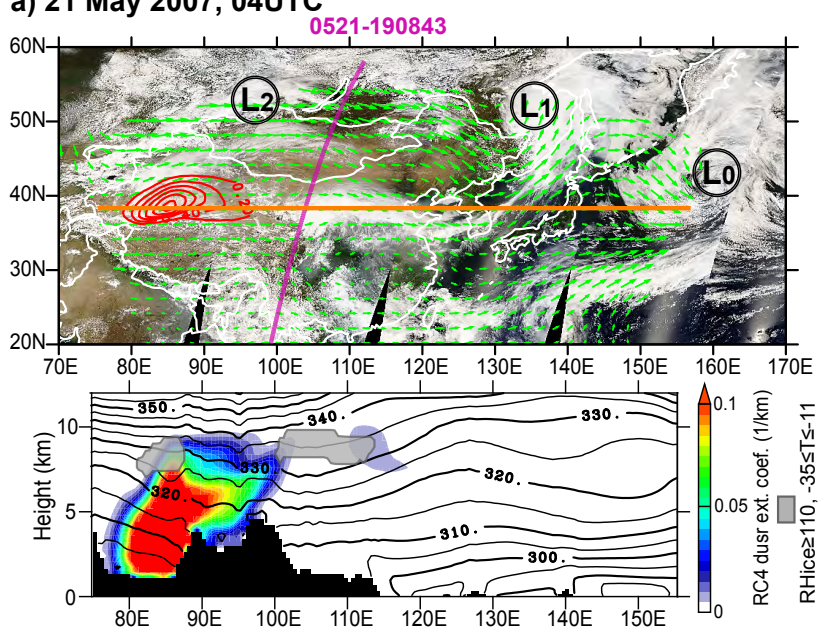

c) 23 May 2007, 04UTC
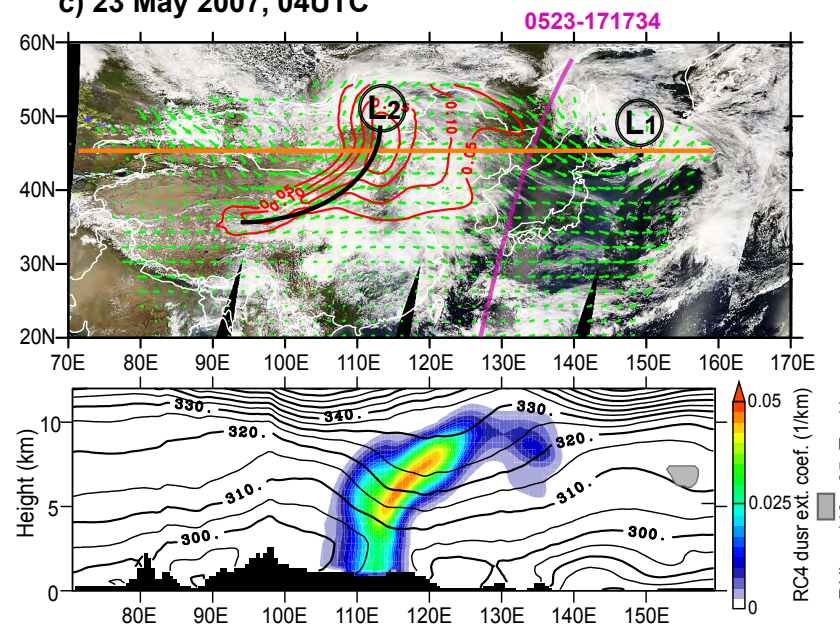

\section{b) 22 May 2007, 04UTC}

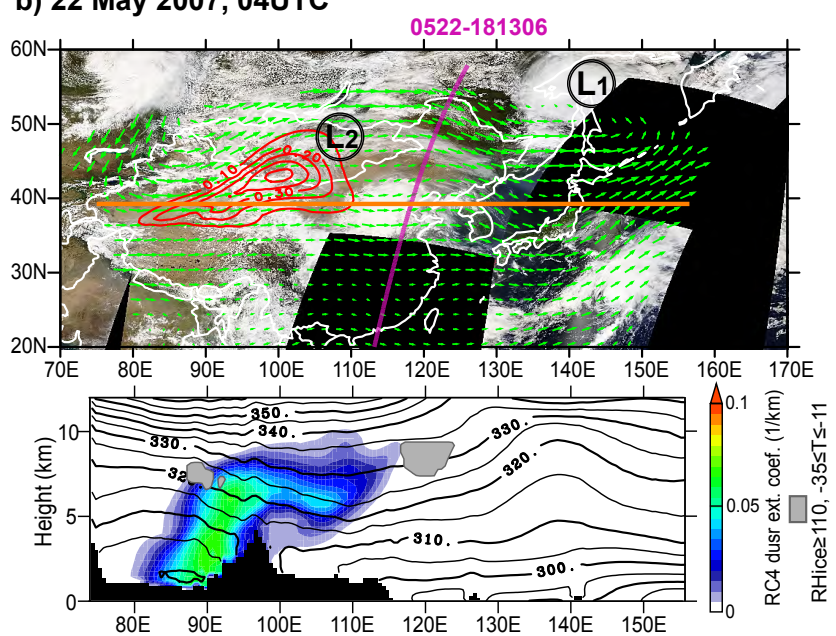

d) 24 May 2007, 04UTC
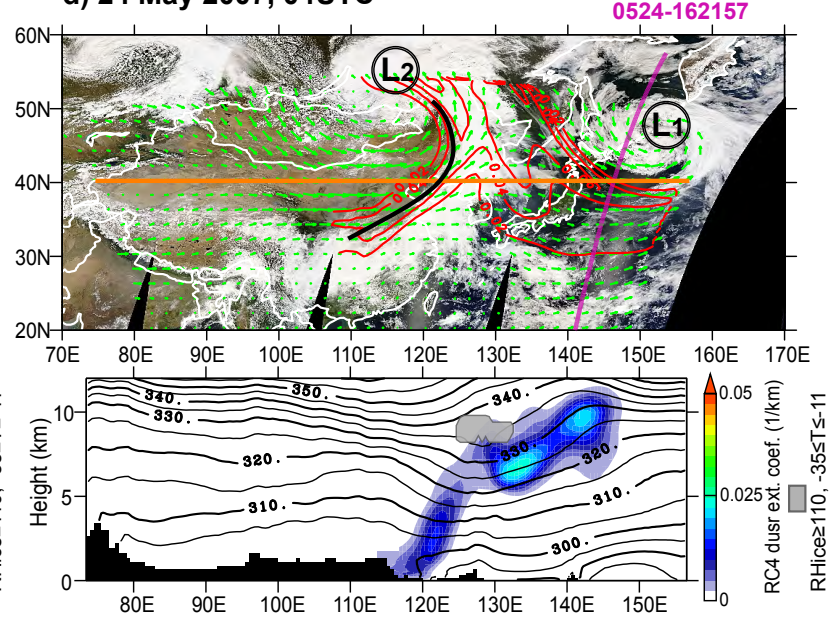

Fig. 6. Day-by-day overview of the daily evolution of dust veil transport from 21 to 24 May. The upper panels show horizontal distributions of the modeled aerosol optical depth (AOD) (red contours) and modeled wind (green vectors) at the RC4 25th layer ( $\sim 8 \mathrm{~km} \mathrm{m.s.1.).} \mathrm{Pink} \mathrm{lines}$ show the CALIPSO orbit paths. The MODIS/Aqua red-green-blue color composite cloud images are also shown, along with the locations of low pressure regions and cold fronts at the surface. Lower panels show cross-sections (along the orange lines in the upper two panels) of the RC4 simulated dust extinction coefficient (color contour), potential temperature (black line), and regions that satisfy the condition of heterogeneous ice formation for mineral dust particles: relative humidity with respect to ice $\left(\mathrm{RH}_{\text {ice }}\right)>110 \%$, and $-35^{\circ} \mathrm{C}<$ temperature $(T)<-11^{\circ} \mathrm{C}$ (gray shading).

center of the dust layer simulated by SPRINTARS was transported at a lower altitude. This may reflect the fact that the global model with a coarser resolution could not properly represent the rapidly changing surface elevation and complicated terrain over the source and surrounding regions, which plays an important role in the injection of dust particles into the upper troposphere (see Sect. 3.1). However, SPRINTARS simulated dust altitudes reasonably closely in areas far from the source region (see the middle and right panels of Fig. 9b).

The SPRINTARS simulation shows that the dust veil travelled at $4-9 \mathrm{~km}$ in altitude with a thickness of $1-4 \mathrm{~km}$, and horizontally at $30-40^{\circ} \mathrm{N}$ over the Pacific Ocean (also see
Fig. 2). The HYSPLIT forward trajectory (Fig. 2b) presented dust passing over the western Pacific at higher latitudes and altitudes than both the CALIOP observation and SPRINTARS simulation. Comparison of vertical profiles near the date line (center panel of Fig. 9b) indicates that the SPRINTARS simulation captured the dust veil quite closely.

The dust veil reached the west coast of North America on 28-29 May at 4-10 km (see also Fig. 2: 28 May-110044 and 29 May-100512 orbits). The dust veil was entrained into the lower troposphere and might have impacted the local air quality over North America. On 31 May (Fig. 2: 31 May063507 orbit), both CALIOP and SPRINTARS detected the dust veil over the North Atlantic Ocean vertically at 2-6 km 


\section{May-190843}

a) CALIPSO dust extinction coef.

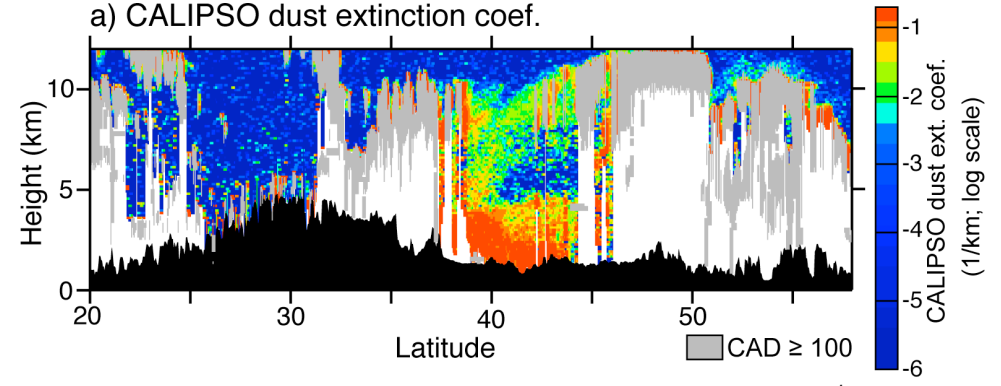

b) RC4 dust ext. coef. (Taklimakan only)

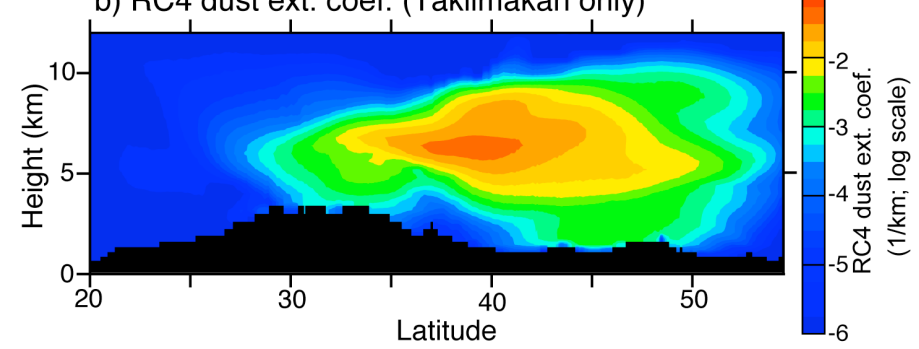

Fig. 7. Cross-sections of the CALIOP and RC4 dust extinction coefficients along the 21 May-190843 orbit path. The color scale ranges for the CALIOP and RC4 data are not consistent.
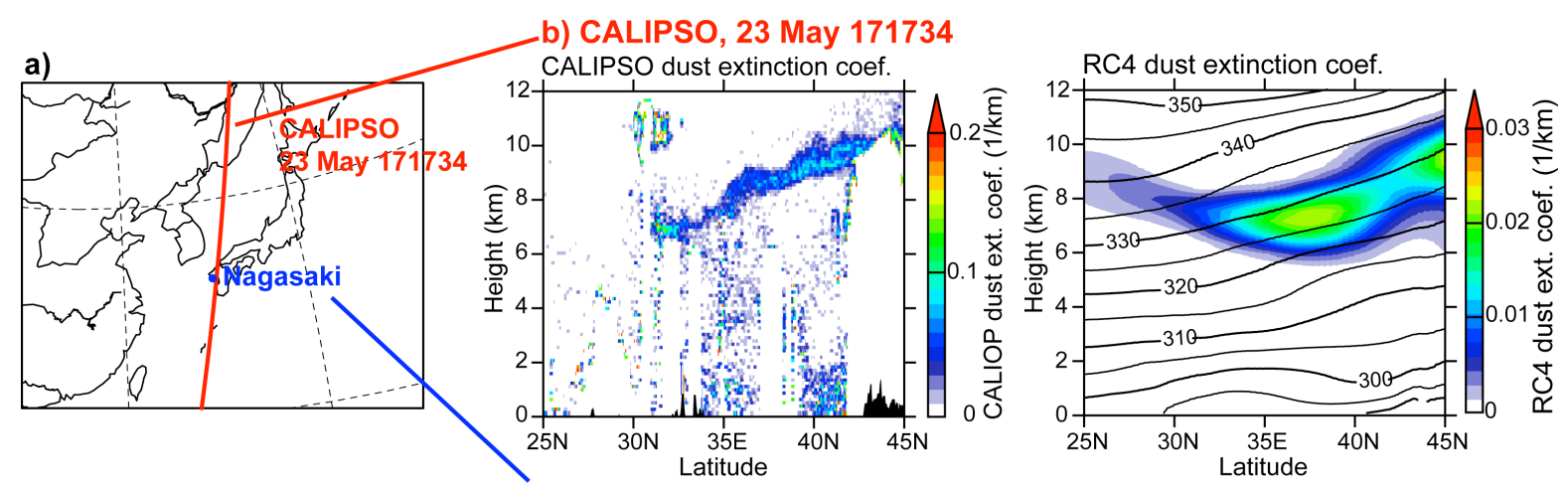

c) Nagasaki
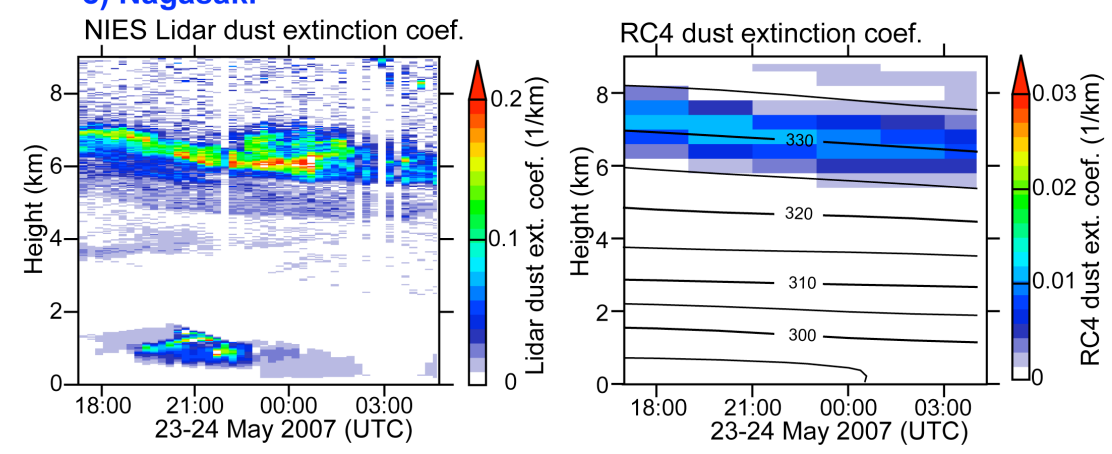

Fig. 8. Comparison of measured and simulated dust extinction coefficients. (a) CALIPSO orbit path and location of the Nagasaki lidar site; (b) cross-sections of the CALIOP measured and RC4 simulated dust extinction coefficients along the CALIPSO orbit shown in (a); (c) time-height cross-sections of the measured NIES lidar and simulated RC4 dust extinction coefficients at the Nagasaki lidar site. Black counter lines in the right panels represent the RC4 potential temperature. The color scale ranges for the observations and RC4 data are not consistent. 


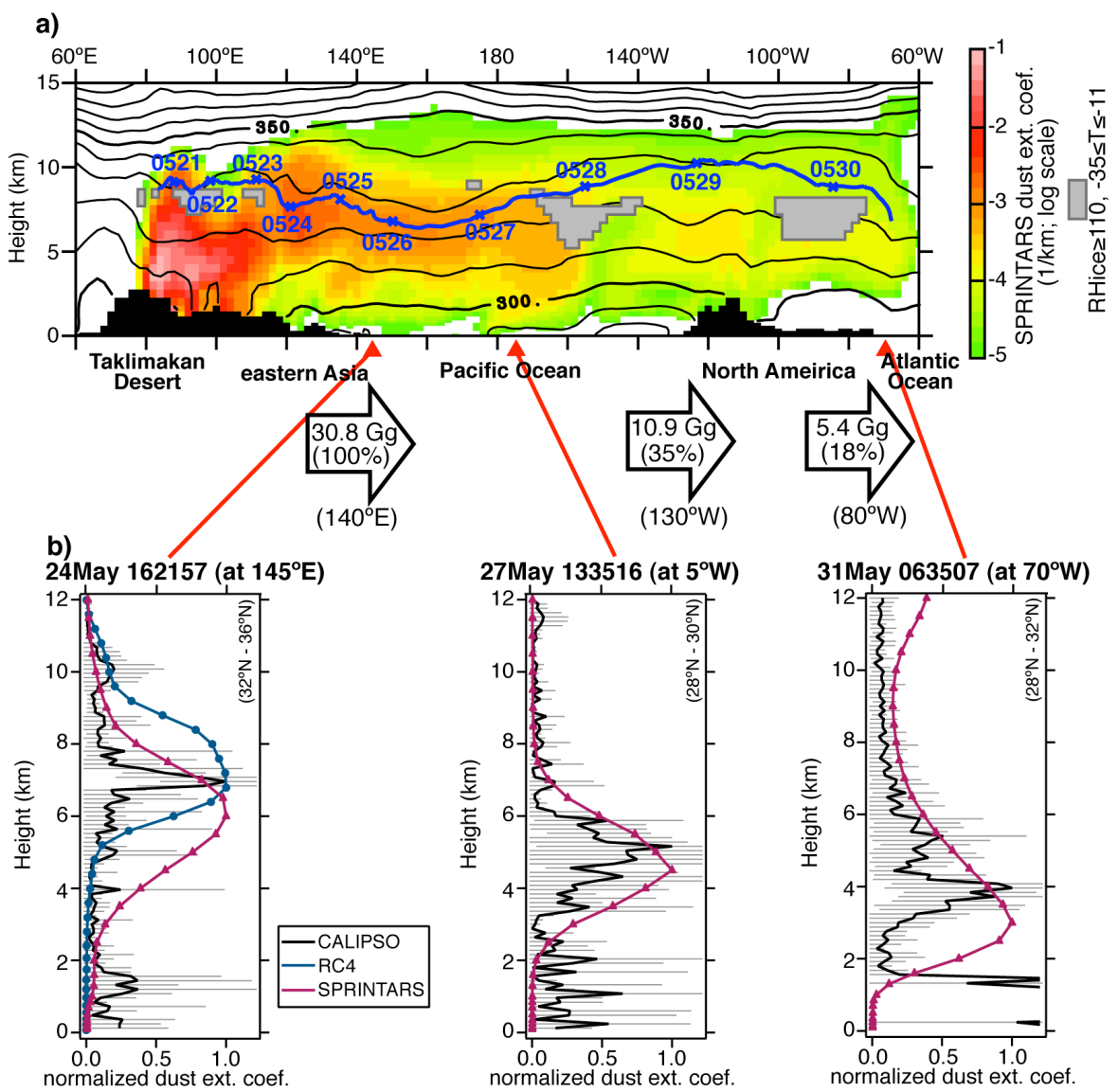

Fig. 9. (a) Vertical longitudinal cross-sections of the SPRINTARS simulated dust extinction coefficient along the HYSPLIT "trajectory A" in Fig. 2b. The modeled potential temperature (black contours) and HYSPLIT trajectory (blue line) are also shown. Gray shading denotes regions that satisfied the condition of heterogeneous ice formation for mineral dust particles: relative humidity with respect to ice $\left(\mathrm{RH}_{\text {ice }}\right)>110 \%$ and $-35^{\circ} \mathrm{C}<$ temperature $(T)<-11^{\circ} \mathrm{C}$. Horizontal dust fluxes at $140^{\circ} \mathrm{E}, 130^{\circ} \mathrm{W}$, and $80^{\circ} \mathrm{W}$ estimated by SPRINTARS are shown by the numbers in the arrows, where the percentage in each bracket is the ratio of the dust amount to that exported to the Pacific through the $140^{\circ}$ E meridian. (b) Normalized vertical profiles of the dust extinction coefficient measured by CALIOP (solid black lines) and simulated by RC4 (blue lines with solid circles) and SPRINTARS (red lines with triangles), along the 24 May-162157, 27 May-133516, and 31 May-063507 CALIOP orbits, respectively. Horizontal error bars represent $\pm 1 \sigma$ of the CALIOP observations. Each profile is calculated by latitudinal averages: averaged regions are given in the panels by latitude.

and horizontally at $25-40^{\circ} \mathrm{N}$ (about $1700 \mathrm{~km}$ ). The dust veil became more scattered vertically than it was over eastern Asia because of the deposition and diffusion of the dust particles (also see Fig. 9b). Grousset et al. (2003) reported that the Asian dust plume emitted in China on 25 February 1990 might have merged with the dust cloud transported from the Sahara Desert over Europe. We were unable to find clear evidence that the dust veil studied in this paper mixed with Saharan dust in the CALIOP measurements, SPRINTARS results, or HYSPLIT trajectory analysis.

The dust veil took 12 days (20-31 May; also see HYSPLIT trajectories in Fig. 2b) to reach the North Atlantic Ocean from the dust source region, corresponding to a transport speed of $\sim 1500 \mathrm{~km} /$ day, consistent with the findings of Grousset et al. (2003) $(20000 \mathrm{~km}$ in 2 weeks based on a trajectory analysis) and Eguchi et al. (2009) (2000 km/day). The SPRINTARS simulation estimated a dust inflow to the Pacific Ocean (at $130^{\circ}$ E) of $30.8 \mathrm{Gg}$ (Fig. 9a). Hara et al. (2008) estimated that the horizontal dust flux over the Taklimakan Desert in summer is $40-50 \mathrm{Gg} /$ day. Uno et al. (2009) tracked the Taklimakan dust transported in one full circuit around the globe, and estimated that $75 \mathrm{Gg}$ of dust was transported to the Pacific Ocean through the $120^{\circ}$ E meridian. SPRINTARS also calculated that $65 \%$ of the transported dust was deposited in the Pacific Ocean (between $140^{\circ} \mathrm{E}$ and $130^{\circ} \mathrm{W}$ ), and $18 \%$ was transported into the North Atlantic Ocean (at $80^{\circ} \mathrm{W}$ ), as shown in Fig. 9a. This implies that the intercontinental transport of the dust veil brought mineral dust particles to remote atmospheres and open oceans far from the Taklimakan Desert. 


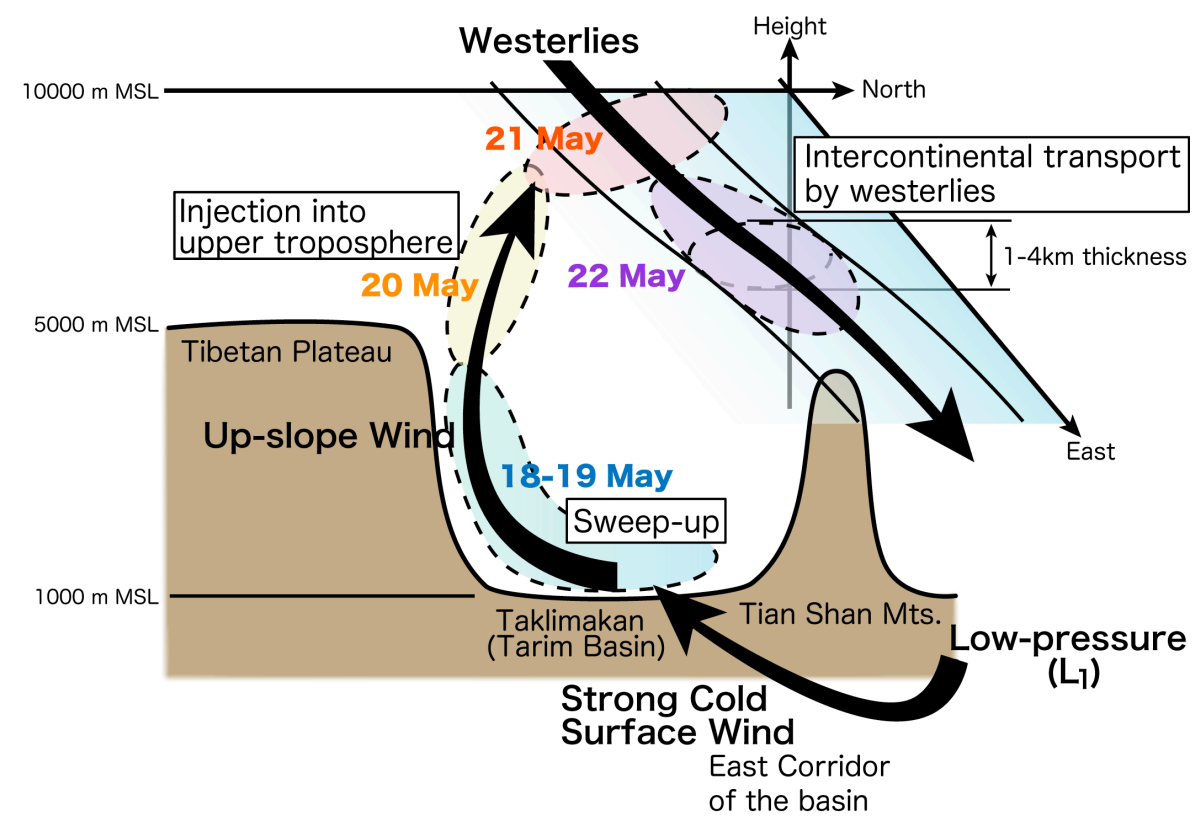

Fig. 10. Schematic of the emission and injection processes of dust over the Taklimakan Desert (Tarim Basin) that formed the dust veil.

Both the global and regional numerical models successfully captured the intercontinental transport of the dust veil, consistent with the CALIOP measurements and HYSPLIT trajectories, although they generally underestimated the dust extinction coefficients (see Figs. 2 and 8). Particularly in North America and the North Atlantic Ocean, the model underestimated the dust extinction coefficient by one to two orders of magnitude. This underestimate led to large uncertainty in the dust deposition amounts. The Taklimakan Desert is located in the Tarim Basin, surrounded on three sides by high mountains (see Fig. 1), which complicates meteorological modeling inside the basin (Uno et al., 2005). The horizontal resolutions of both models may be insufficient to capture the sharply changing terrain, detailed wind fields, and dust emission. This may be one reason for the underestimation of dust emission in our model simulations. Compared to the dust concentrations derived from SYNOP visibility measurements, the RC4 model underestimated dust concentrations considerably in the source region (Fig. 5). The observed dust veil was only $1-2 \mathrm{~km}$ thick from eastern Asia to the Pacific Ocean. The vertical resolutions of both models may be still too coarse to reproduce such a fine structure and may be another cause for the underestimation of dust extinction coefficients. Simulations with better spatial resolution and data assimilation methods (e.g. Yumimoto et al., 2007, 2008) may reduce the uncertainty of quantitative estimates in the future.

\section{Concluding remarks}

CALIOP onboard the CALIPSO satellite tracked a highly lofted, extensive dust veil travelling over eastern Asia, the Pacific Ocean, North America, and the Atlantic Ocean, which was generated in an intensive dust storm during 1920 May 2007 in the Taklimakan Desert. By combining multiple observation datasets and analysis tools, we comprehensively investigated the dust emission and injection processes over the source region to understand the generation mechanism of the dust veil, along with its subsequent intercontinental transport and 3-D structure.

The regional RC4 model was used to analyze the emission and injection processes of the dust veil over the source region, in combination with passive satellite measurements and ground weather observations. During 19-20 May, strong northeasterly surface winds associated with a low pressure region blew into the Tarim Basin through the eastern corridor, moving large amounts of dust into the air. Meanwhile, strong updraft winds along the northern slope of the Tibetan Plateau brought airborne dust particles up to the upper troposphere (about $9 \mathrm{~km}$ m.s.l.). The highly lofted dust particles in the upper troposphere were then transported eastward by the westerly. The SYNOP surface weather observations recorded persistently low visibilities $(<1 \mathrm{~km})$ over the basin, indicating that the dust event was exceptionally intensive. Two mechanisms played a key role in the formation of the dust veil in the Taklimakan Desert. One was the presence of strong surface winds associated with low pressures in the basin, which blew up massive amounts of dust from the ground and into the atmosphere. The other was the formation of a strong updraft by 
the high and steep mountain slopes of the Tibetan Plateau on the southern side of the basin. The strong updraft could lift the suspended dust into the upper troposphere, where westerlies were dominant. Figure 8 shows a schematic summarizing the emission and injection processes of the dust veil over the Taklimakan Desert.

The simulation results of the global SPRINTARS model showed close agreement with the CALIOP measurements, revealing that the dust veil was transported at $4-10 \mathrm{~km}$ along the isentropic surface of $310-340 \mathrm{~K}$ with a thickness of 1$4 \mathrm{~km}$. The SPRINTARS and HYSPLIT trajectory analyses estimated that the dust veil took 12 days (20-31 May) to travel from the Taklimakan Desert to the North Atlantic, yielding a transport speed of $\sim 1500 \mathrm{~km} /$ day, consistent with the results of other studies. The dust amount exported into the Pacific Ocean was estimated to be $30.8 \mathrm{Gg}$, of which $65 \%$ was deposited in the Pacific Ocean and $18 \%$ was transported to the North Atlantic. This implies that dust particles from the Taklimakan Desert can fertilize not only the Pacific Ocean, but also the North Atlantic. These dusts also contribute to the background dust in the free atmosphere and affect the radiative budget at high altitudes through scattering and absorption.

During its extraordinary long-range transport, the dust veil reached altitudes where it could have created nucleation sites for ice clouds (Sakai et al., 2004; Sassen et al., 2003). The air masses along the dust transport track that satisfied the conditions of heterogeneous ice formation are indicated by gray shading in Figs. 2, 6, and 9. In these areas, relative humidity with respect to ice $\mathrm{RH}_{\text {ice }}$ was $>110 \%$ and temperature $(T)$ was $>-35^{\circ} \mathrm{C}$ and $<-11^{\circ} \mathrm{C}$ (Isono and Ikebe, 1960; Bailey and Hallett, 2002). These regions partly correlate with cloud regions classified by the CALIOP CAD index (Fig. 2), indicating a high possibility that the dust veil affected ice cloud formation. Further analyses and observations are necessary to provide conclusive evidence.

Acknowledgements. This study was supported in part by the Research Fellowships of the Japan Society for the Promotion of Science (JSPS) for Young Scientists program (21-3928) and the Grant-in-Aid for Scientific Research in Priority Areas "Western Pacific Air-Sea Interaction Study (W-PASS)" under Grant No. 18067005 from the Ministry of Education, Culture, Sports, Science and Technology (MEXT), Japan.

Edited by: R. von Glasow

\section{References}

Aoki, I., Kurosaki, K., Osada, R., Sato, T., and Kimura, F.: Dust storms generated by mesoscale cold fronts in the Tarim Basin, Northwest China, Geophys. Res. Lett., 32, L06807, doi:10.1029/2004GL021776, 2005.

Bailey, M. and Hallette, J.: Nucleation effects on the habit of vapor grown ice crystal from -18 to $-42^{\circ} \mathrm{C}$, Q. J. Roy. Meteorol. Soc., 128, 1461-1483, 2002.
Bohren, C. F. and Huffman, D. R.: Absorption and Scattering of Light by Small Particles, John Wiley, New York, 1983.

Bory, A. J.-M., Biscaye, P. E., and Grousset, F. E.: Two distinct seasonal Asian source regions for mineral dust deposited in Greenland (NorthGRIP), Geophys. Res. Lett., 30(4), 1167, doi:10.1029/2002GL016446, 2003.

Draxler, R. R. and Hess, G. D.: An overview of the HYSPLIT_4 modeling system for trajectory, dispersion, and deposition, Aust. Meteorol. Mag., 47, 295-308, 1998.

Duce, R. A., Liss, C. K., Merrill, J. T., Atlas, E. L., Buat-Menard, P., Huck, B. B., Miller, J. M., Prospero, J. M., Arimoto, R., Church, T. M., Ellis, W., Galloway, J. N., Hassen, L., Jickells, T. D., Knap, A. H., and Reinhardt, K. H.: The atmospheric impact of trace species to the world ocean, Global Biogeochem. Cy., 5, 193-259, 1991.

Eguchi, K., Uno, I., Yumimoto, K., Takemura, T., Shimizu, A., Sugimoto, N., and Liu, Z.: Trans-pacific dust transport: integrated analysis of NASA/CALIPSO and a global aerosol transport model, Atmos. Chem. Phys., 9, 3137-3145, 2009,

http://www.atmos-chem-phys.net/9/3137/2009/.

Fernald, F. G.: Analysis of atmospheric LIDAR observations: Some comments, Appl. Optics, 23, 652-653, 1984.

Generoso, S., Bey, I., Labonne, M., and Bréon, F.-M.: Aerosol vertical distribution in dust outflow over the Atlantic: Comparisons between GEOS-Chem and Cloud-Aerosol Lidar and Infrared Pathfinder Satellite Observation (CALIPSO), J. Geophys. Res., 113, D24209, doi:10.1029/2008JD010154, 2008.

Grousset, F. E., Ginoux, P., Bory, A., and Biscaye, P. E.: Case study of a Chinese dust plume reaching the French Alps, Geophys. Res. Lett., 30(6), 1277, doi:10.1029/2002GL016833, 2003.

Kurosaki, Y. and Mikami, M.: Recent frequent dust events and their relation to surface wind in East Asia, Geophys. Res. Lett., 30(14), 1736, doi:10.1029/2003GL017261, 2003.

Hara, Y., Uno, I., Yumimoto, K., Tanaka, M., Shimizu, A., Sugimoto, N., and Liu, Z.: Summertime Taklimakan dust structure, Geophys. Res. Lett., 35, L23801, doi:10.1029/2008JD035630, 2008.

Hara, Y., Yumimoto, K., Uno, I., Shimizu, A., Sugimoto, N., Liu, Z., and Winker, D. M.: Asian dust outflow in the PBL and free atmosphere retrieved by NASA CALIPSO and an assimilated dust transport model, Atmos. Chem. Phys., 9, 1227-1239, 2009, http://www.atmos-chem-phys.net/9/1227/2009/.

Husar, R. B., Tratt, D. M., Schichtel, B. A., et al.: Asian dust events of April 1998, J. Geophys. Res., 106(D16), 18317-18330, 2001.

Huang, J., Minnis, P., Chen, B., Huang, Z., Liu, Z., Zhao, Q., Yi, Y., and Ayers, J. K.: Long-range transport and vertical structure of Asian dust from CALIPSO and surface measurements during PACDEX, J. Geophys. Res., 113, D23212, doi:10.1029/2008JD010620, 2008.

Isono, K. and Ikebe, Y.: On the ice-nucleating ability of rockforming minerals and soil particles, J. Meteorol. Soc. Jpn., 38, 211-233, 1960.

Liu, Z., Liu, D., Huang, J., Vaughan, M., Uno, I., Sugimoto, N., Kittaka, C., Trepte, C., Wang, Z., Hostetler, C., and Winker, D.: Airborne dust distributions over the Tibetan Plateau and surrounding areas derived from the first year of CALIPSO lidar observations, Atmos. Chem. Phys., 8, 5045-5060, 2008, http://www.atmos-chem-phys.net/8/5045/2008/.

Liu, Z., Omar, A., Vaughan, M., Hair, J., Kittaka, C., Hu, Y., Powell, 
K., Trepte, C., Winker, D., Hostetler, C., Ferrare, R., and Pierce, R.: CALIPSO lidar observations of the optical properties of Saharan dust: A case study of long-range transport, J. Geophys. Res., 113, D07207, doi:10.1029/2007JD008878, 2008b.

Martin, J. H., Coale, K. H., Johnson, K. S., et al.: Testing the iron hypothesis in ecosystems of the equatorial Pacific Ocean, Nature, 371, 123-129, 1994.

Matsuki, A., Iwasaka, Y., Osada, K., et al.: Seasonal dependence of the long-range transport and vertical distribution of free tropospheric aerosols over East Asia: On the basis of aircraft and lidar measurements and isentropic trajectory analysis, J. Geophys. Res., 108(D23), 8663, doi:10.1029/2002JD003266, 2003.

McKendry, I. G., Hacker, J. P., Stull, R., Sakiyama, S., Mignacca, D., and Reid, K.: Long-range transport of Asian dust to the Lower Fraser Valley, British Columbia, Canada, J. Desert Res., 106, 18361-18370, 2001.

Prospero, J. M., Ginoux, P., Torres, O., Nicholson, S. E., and Gill, T. E.: Environmental characterization of global sources of atmospheric soil dust indentified with the NIMBUS 7 Total Ozone Mapping Spectrometer (TOMS) absorbing aerosol product, Rev. Geophys., 40(1), 1002, doi:10/1029/2000RG000095, 2002.

Sakai, T., Nagai, T., Nakazawa, M., and Matsumura, T.: Raman lidar measurement of water vapor and ice clouds associated with Asian dust layer over Tsukuba, Japan, Geophys. Res. Lett., 31, L06128, doi:10.1029/2003GL019332, 2004.

Sassen, K.: Indirect climate forcing over the western US from Asian dust storms, Geophys. Res. Lett., 29, 1465, 2002.

Sassen, K., DeMott, P. J., Prospero, J. M., and Poellot, M. R.: Saharan dust storms and indirect aerosol effect on clouds: CRYSTAL-FACE results, Geophys. Res. Lett., 30(12), 1633, doi:10.1029/2003GL017371, 2003.

Shao, Y., Yang, Y., Wang, J., Song, Z., Lesile, L. M., Dong, C., Zhang, Z., Lin, Z., Kanai, Y., Yabuki, S., and Chun, Y.: Northeast Asian dust storms: Real-time numerical prediction and validation, J. Geophys. Res., 108, 4691, doi:10.1029/2003JD003667, 2003.

Shimizu, A., Sugimoto, N., Matsui, I., Tatarov, B., Xie, C., Nishizawa, T., and Hara, Y.: NIES lidar Network; strategies and applications, $24^{r d}$ International Laser Rader Conference, 2328 June 2008, Boulder, Colorado, USA, 24ILRC, ISBN 9780-615-21489-4, 707-710, 2008.

Shimizu, A., Sugimoto, N., Matsui, I., Arao, K., Uno, I., Murayama, T., Kagawa, N., Aoki, K., Uchiyama, A., and Yamazaki, A.: Continuous observations of Asian dust and other aerosols by polarization lidars in China and Japan during ACE-Asia, J. Geophys. Res., 109, D19S17, doi:10.1029/2002JD003253, 2004.

Sokolic, I. N. and Toon, O. B.: Direct radiative forcing by anthropogenic airborne mineral aerosols, Nature, 381, 681-683, 1996.
Sun, J., Chang, M., and Liu, T.: Spatial and temporal characteristics of dust storms in China and its surrounding regions, 19601999: Relations to source area and climate, J. Geophys. Res., 106, 18331-18344, 2001.

Takemura, T., Nozawa, T., Emori, S., Nakajima, T. Y., and Nakajima, T.: Simulation of climate response to aerosol direct and indirect effect with aerosol transport-radiation model, J. Geophys. Res., 110, D02202, doi:10.1029/2004JD005029, 2005.

Tegen, I. and Fung, I.: Modeling of mineral dust in the atmosphere: Sources, transport, and optical thickness, J. Geophys. Res., 99, 22897-22914, 1994.

Twomey, S.: The influence of pollution on the shortwave albedo of clouds, J. Atmos. Sci., 34, 1149-1152, 2002.

Uno, I., Satake, S., Carmichael, G. R., et al.: Numerical study of Asian dust transport during the springtime of 2001 simulated with the Chemical Weather Forecasting System (CFORS) model, J. Geophys. Res., 109, D19S24, doi:10.1029/2003JD00422, 2004.

Uno, I., Harada, K., Satake, S., Hara, H., and Wang, Z.: Meteorological characteristics and dust distribution of the Tarim Basin simulated by the nesting RAMS/CFORS dust model, J. Meteorol. Soc. Jpn., 83A, 219-239, 2005.

Uno, I., Yumimoto, K., Shimizu, A., Hara, Y., Sugimoto, N., Wang, Z., Liu, Z., and Winker, D. M.: 3-D structure of Asian dust transport revealed by CALIPSO lidar and a 4DVAR dust model, Geophys. Res. Lett., 35, L06803, doi:10.1029/2007GL032329, 2008.

Uno, I., Eguchi, K., Yumimoto, K., Takemura, T., Shimizu, A., Uematsu, M., Liu, Z., Wang, Z., Hara, Y., and Sugimoto, N.: Asian dust transported one full circuit around the globe, Nat. Geosci., 2, 557-560, 2009.

Winker, D. M., Hunt, W. H., and McGill, M. J.: Initial performance assessment of CALIOP, Geophys. Res. Lett., 34, L19803, doi:10.1029/2007GL030135, 2007.

Yu, H., Dickinson, R. E., Chin, M., Kaufman, Y. J., Holben, B. N., Geogdzhayev, I. V., and Mishchenko, M. I.: Annual cycle of global distribution of aerosol optical depth from integration of MODIS retrievals and GOCART model simulation, J. Geophys. Res., 108(D3), 4128, doi:10.1029/2002JD002717, 2003.

Yumimoto, K., Uno, I., Sugimoto, N., Shimizu, A., and Satake, S.: Adjoint inversion modelling of dust emission and transport over East Asia, Geophys. Res. Lett., 34, L08806, doi:10.1029/2006GL028551, 2007.

Yumimoto, K., Uno, I., Sugimoto, N., Shimizu, A., Liu, Z., and Winker, D. M.: Adjoint inversion modeling of Asian dust emission using lidar observations, Atmos. Chem. Phys., 8, 28692884, 2008, http://www.atmos-chem-phys.net/8/2869/2008/. 